no overall trends in the recalled frequency of pesticide application in the Ugandan cohort, where reassessment occurred 2 years later. Initial results in the UK, where re-assessment took place many years later, suggested overestimation of years working with pesticides (Geometric Mean Ratio $=1.25$ [95\% CI: 1.16 to 1.36$]$ ). The UK participants reported more frequent use of PPE items than in Uganda, which was mostly limited to long-trousers, shirt, and boots; however, recall ability was similar (mostly $>70 \%$ agreement). The reporting of specific crops involving pesticide use was low among Ugandan farmers, who cultivated many crops (e.g., only 13\% could recall all three major crops). Sensitivity of reported crop use in the UK appeared to be lower (<40\%) with a longer recall period.

Conclusion Our results to date suggest limited evidence of recall bias, which appears to differ based on the specific exposure determinant and length of recall period.

\section{0-307 PERMETHRIN USE AND CIRCULATING IMMUNOLOGIC MARKERS: A LONGITUDINAL INVESTIGATION IN THE BIOMARKERS OF EXPOSURE AND EFFECT IN AGRICULTURE STUDY}

'Vicky C Chang, Joseph J Shearer, Danping Liu, Gabriela Andreotti, Christine G Parks, Dale P Sandler, Michael C Alavanja, Ola Landgren, Laura Beane Freeman, Jonathan Hofmann. ${ }^{1}$ U.S. National Cancer Institute, United States

\subsection{6/OEM-2021-EPI.98}

Introduction Permethrin is one of the most widely used insecticides in the United States. Previous studies have reported associations of permethrin use with increased risk of multiple myeloma (MM) and its precursor, monoclonal gammopathy of undetermined significance (MGUS). Biological mechanisms underlying these associations remain unclear, with some evidence linking permethrin to altered hematological parameters, underscoring the need to further explore immunologic markers related to permethrin exposure.

Objective Evaluate associations between recent occupational permethrin use and circulating levels of immunologic markers. Methods We conducted a longitudinal investigation among 33 male permethrin applicators $\geq 50$ years of age in the Biomarkers of Exposure and Effect in Agriculture study who had blood samples collected in the offseason and within a day after permethrin application (recent use); 27 of these applicators also had a sample collected $\sim 3$ weeks after permethrin use. As an external comparison, we analyzed one-time blood samples from 70 age-matched non-farming controls. Serum levels of 87 immunologic markers were assessed using a multiplex immunoassay. Multivariable linear mixed models were used to estimate associations between permethrin use and immunologic markers.

Results Among pesticide applicators, recent permethrin use (vs. offseason) was associated with increased serum caspase-8 (mean relative (fold)-change in protein concentration: 1.36; 95\% confidence interval: 1.04-1.78) and arginase-1 (1.24; $1.00-1.53)$ and reduced pleiotrophin $(-1.15 ;-1.26,-1.05)$ and matrix metalloproteinase-12 (MMP-12; -1.12; -1.26, 1.00) levels. Associations with caspase-8, arginase-1, and pleiotrophin persisted at $\sim 3$ weeks after permethrin use (vs. offseason). Compared to non-farming controls, we also observed increased caspase-8 $(1.44 ; 1.10-1.88)$ and reduced MMP-12 (-
$1.31 ;-1.61,-1.06)$ levels among applicators after recent permethrin use, with associations persisting $\sim 3$ weeks after use. Conclusion Although exploratory, these findings suggest that permethrin use may be associated with certain immunologic markers previously implicated in MGUS/MM pathogenesis, particularly caspase- 8 and MMP-12, which are involved in apoptosis and angiogenesis, respectively.

\section{0-406 EXPOSURE TO CHLOROACETAMIDE HERBICIDES IN AGRICULTURE AND LYMPHOID MALIGNANCIES, OVERALL AND BY SUBTYPES, IN THE AGRICULTURE AND CANCER (AGRICAN) COHORT.}

${ }^{1}$ Amandine Busson, Mathilde Boulanger, Matthieu Meryet-Figuière, Stephanie Perrier, Alain Monnereau, Isabelle Baldi, Séverine Tual, Pierre Lebailly. 'Institut National de la Santé et de la Recherche Médicale (INSERM), France

\subsection{6/OEM-2021-EPI.99}

Introduction Since the $80 \mathrm{~s}$, more and more epidemiological studies demonstrated a relationship between agricultural exposures - especially pesticide use - and Lymphoid Malignancies (LM). However, the role of specific pesticides remains little explored.

Objective We assessed the relationship between chloroacetamide herbicide exposure (as a group and for specific molecules: acetochlore, alachlor, dimethachlore, DMTA, DMTA-p, flufenacet, S-metolachlor, metolachlor metazachlor, napropamide, pethoxamid) and LM overall and by main subtypes: multiple myeloma (MM), Chronic Lymphocytic Leukemia/ Small Lymphocytic Lymphoma (CLL/SLL), Diffuse Large B-cell Lymphoma (DLBCL).

Methods Lifetime occupational pesticide use on 11 crops were collected from 181,842 people enrolled in the cohort AGRICAN. Incident cases were identified by cross-linkage with population-based cancer registries until 2015. Exposure to 11 chloroacetamides (ever/never) was estimated based on the crop-exposure matrix PESTIMAT.

Results Incident cases included 1,349 LM, 319 MM, 298 CLL/SLL and 221 DLBCL. Among the 51,889 pesticide users, $44 \%$ were exposed to chloroacetamides $(n=22,862$ including 95.4\% men), ranging from $7.8 \%(n=4,059)$ for dimethachlore to $28.7 \%(n=14,871)$ for metolachlor/S-metolachlor. Positive associations were reported between chloroacetamide use on any crop and $\mathrm{LM}(\mathrm{HR}=1.33,95 \% \mathrm{CI}=1.12-1.59)$, CLL/SLL $(\mathrm{HR}=1.66,95 \% \mathrm{CI}=1.15-2.39)$ and $\mathrm{MM} \quad(\mathrm{HR}=1.37,95 \%$ $\mathrm{CI}=0.95-1.96)$, especially on corn. In addition, specific associations were observed in some categories of farmers: LM overall and CLL/SLL in vinegrowers, LM in beet-growers, LM and DLBLC in rape-growers and MM in potatoes-growers. Exposure to some active ingredients were significantly associated with i) LM: acetochlor, DMTA, flufenacet, alachlor, metazachlor, metolachlor (risks from 1.32 to 1.43); (ii) CLL/SLL: alachlor, metolachlor (risks from 1.75 to 1.79). Trends to increased risks were also observed between (i) LM and DMTA-p or napropamide, (ii) CLL/SLL and napropamid, (iii) $\mathrm{MM}$ and alachlor or metolachlor and (iii) DLBCL and dimetachlor or metazachlor.

Conclusion We found positive associations between LM overall incidences and some subtypes, and exposure to chloroacetamide as a group or considering specific molecules. 